\title{
Evaluation of European Reusable VTVL Booster Stages
}

\author{
Stappert, S..$^{*}$, Wilken, J. ${ }^{1}$, Sippel, M. ${ }^{1}$, Dietlein, I. ${ }^{1}$ \\ German Aerospace Center (DLR), Institute of Space Systems, Robert-Hooke-Straße 7, 28359 Bremen, Germany
}

\begin{abstract}
Reusability of launch systems has the potential to strongly impact the launch service market if sufficient reliability and low refurbishment costs can be achieved. This study focuses on the vertical takeoff and vertical landing (VTVL) method as currently used by SpaceX. The goal of this study is to determine the impact of this method on a technical, operational and economic level and to identify its potential for a future European reusable launch system. Therefore, different propellant combinations, stagings and engine cycles were considered for a launch system with a reusable VTVL booster stage and a payload capability of 7 tons to GTO (geostationary transfer orbit). Several concepts were subjected to a preliminary design phase and are presented in this paper. The most promising concept will be selected to enter a second, more detailed design phase to obtain a feasible reusable VTVL launcher with the potential to become a future European launch vehicle.
\end{abstract}

\section{Nomenclature}

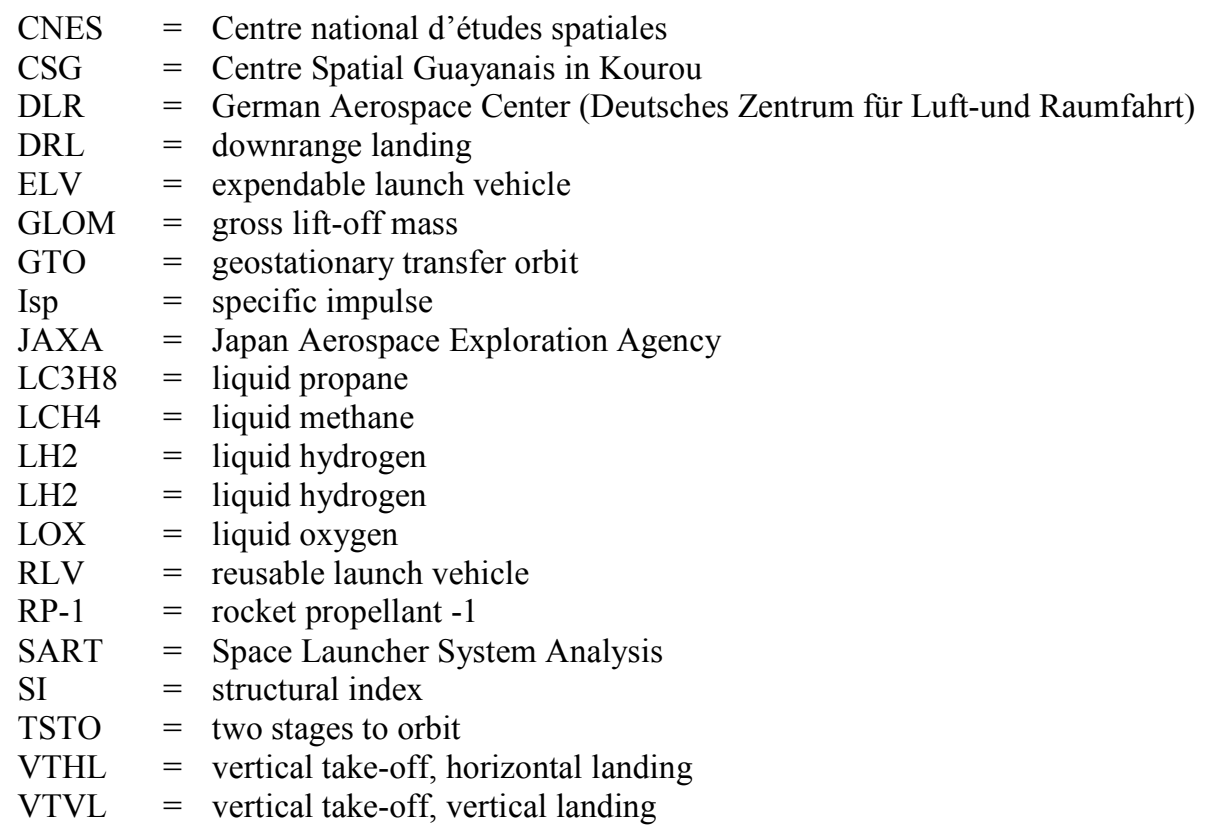

\section{Introduction}

Reusability in space transport can have a strong impact on launch costs and thus competitiveness on the launch market. However, the historic Space Shuttle system, consisting of two reusable solid booster stages and a fully reusable winged Orbiter with crew compartments, showed that reusability can also lead to increasing launch costs if refurbishment costs cannot be kept low.

\footnotetext{
* Scientific Employee, Space Launcher Systems Analysis (SART), German Aerospace Center (DLR), Young Professional AIAA Member
} 
Nonetheless, the recent successes of SpaceX (with Falcon 9 and Falcon Heavy) and Blue Origin (New Shephard) in landing, recovering and reusing their respective booster stages by means of retropropulsion have shown the possibility of developing, producing and operating reusable launchers at low launch service costs that are able to compete on the current launch market worldwide. Hence, the need in Europe to thoroughly investigate different methods of reusability to keep up with the evolving launch market has become of essential importance [1-3].

Several studies on partly or fully reusable first stages using different return methods have been conducted in the past at DLR. The liquid fly-back booster concept was studied extensively during the early 2000s [4]. This concept features a winged first stage equipped with aerodynamic control surfaces to perform a lift-supported re-entry after MECO (Main Engine Cutoff), slowing the booster down from hypersonic to subsonic speeds. When reaching subsonic speed, the winged stage would either switch on several air-breathing turbo-engines to fly back to the launch site or would be captured by an airplane to be towed back to its landing site [5]. However, through the recent successes using the ballistic retro-propulsion method the interest in studying and understanding this method has further increased. Thus, in the past year, an extensive study on both VTHL (vertical takeoff, horizontal landing) and VTVL (vertical takeoff, vertical landing) stages has begun in the framework of the DLR X-TRAS project [2]. This study, in the following referred to as ENTRAIN study (European Next Reusable Ariane), focuses on identifying the impact of both methods on performance, mass, structure, recovery hardware, operations and finally launch costs.

\section{A. Study Logic and High-Level Assumptions}

The ENTRAIN study is divided into two parts: the first part focuses on comparing VTVL and VTHL launchers while emphasizing on optimizing the launch systems to a comparative level in order to avoid distortions by different optimization levels. Therefore, the same high-level requirements and assumptions are used for both return methods. In this paper, the VTVL launchers investigated in the framework of this first half of ENTRAIN are presented. The high-level requirements and considered propellant combinations, engine cycles and stagings are the following:

- $7000 \mathrm{~kg}+500 \mathrm{~kg}$ margin payload to GTO of $250 \mathrm{~km}$ x $35786 \mathrm{~km} \times 6^{\circ}$ (standard Ariane 5 GTO) via a LEO parking orbit of $140 \mathrm{~km} \times 330 \mathrm{~km} \times 6^{\circ}$ (see section IV.E for details)

- Launch from CSG, Kourou

- TSTO: Two Stage to Orbit

- Same propellant combination in both stages

- Same engines in both stages with exception of different nozzle expansion ratios (as for Ariane 4 1st stage and 2nd stage engine)

- Engine Cycles: Gas Generator (GG) and Staged Combustion (SC)

- VTVL with retropropulsion landing on downrange barge (DRL) or with return-to-launch-site (RTLS)

- 2nd stage $\Delta \mathrm{v}$ of $6.2 \mathrm{~km} / \mathrm{s}, 6.6 \mathrm{~km} / \mathrm{s}, 7.0 \mathrm{~km} / \mathrm{s}, 7.6 \mathrm{~km} / \mathrm{s}$

- Propellant Combinations: LOX/LH2, LOX/LCH4, LOX/LC3H8, LOX/RP-1

In the first half of the study, two different design phases were defined. The first design phase used a simplified, preliminary mass estimation model to determine the launchers' dry mass by using structural index curves derived from historical and current launchers. The results of this first design phase are presented in [2] and are briefly described in section III of this paper.

The results of this first design phase were used to select certain launcher concepts that were subjected to a second design phase. In this second design phase a more detailed mass estimation model was established. Furthermore, this second phase design model includes modeling of the propellant system, the engines and engine cycles, the tank, interstage and skirt structure and features a refined mass estimation of several subsystems. Thus the accuracy and level of detail of the designed launchers could be increased compared to the first design phase. This paper focuses mainly on the launchers designed in the second phase of the study. The assumptions and methods used in this particular phase are described in section IV and results are presented in section V.

At the end of this comparative part of the ENTRAIN study, one promising return concept for each the VTVL and the VTHL method will be selected to enter the second half of the study, called ENTRAIN 2, with the aim to obtain realistic designs for an operational and viable launch system and to identify required technology developments depending on the return mode (see section VI). 


\section{First Designs based on Structural Index Assumptions}

\section{A. Assumptions}

The general layout of all launchers follows the same principle; both stages use the same propellant combination and the same engines with slight modifications (vacuum adapted engine nozzle in the upper stage). This approach is considered cost-effective since only one type of engine has to be developed and produced. Furthermore, only the first stage is recovered by using retro-propulsion of the own rocket engines. Further hardware necessary for recovery are aerodynamic control devices (e.g. grid fins or conventional fins) for aerodynamic steering of the stage and deployable landing legs to allow for a soft and stable landing. Fig. 1 shows the general layout of the designed launchers. As can be seen the launchers consist of (from bottom to top) a rear skirt containing the first stage engines, the two first stage tanks separated by a common bulkhead, an interstage accommodating the second stage engine nozzle, the second stage tanks and a fairing.

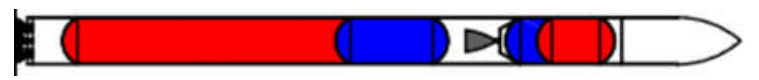

Fig. 1: Generic layout of designed launchers

In the first design phase, the respective launchers were designed using structural indices derived from actual and historical launchers to estimate the dry mass. Since no actual launchers using methane and propane were built, the corresponding structural index formula was interpolated by using the bulk densities and known structural indices of the LOX/LH2 and LOX/RP-1 propellant combinations. The engine mass was calculated with the DLR-SART software $\operatorname{lrp}$ (liquid rocket propulsion). The mass of the grid fins and landings legs was estimated by scaling the respective masses of the Falcon 9 with the dry mass of the ENTRAIN launchers. A detailed explanation of the assumptions and methods used for this first design phase is given in [2].

Only the LOX/LH2 launchers were calculated using different engine cycles, namely staged combustion and gas generator (see section IV.A for more detail), while all other launchers were designed using the gas generator cycle. The gas generator cycle is considered more cost-efficient since gas generator engines are less complex and thus development and production are not as expensive as for staged combustion engines. Furthermore, staged combustion engines are generally heavier than gas generator engines for the same thrust level. However, the staged combustion cycle offers a higher specific impulse which allows building compacter launchers.

In the first design phase two different landing options were considered; the RTLS method with landing at or close to the launch site and the DRL method with landing on a barge downrange. The advantage of the former is the fact that the rocket is brought back to the launch site, thus minimizing recovery effort and turnaround times. However, the RTLS method has the drawback of severely reducing the performance and the maximum payload mass, since more propellant is required for the return manoeuvers [1]. In case of an RTLS landing three burns are performed: the boostback burn (setting the trajectory towards the landing site), the re-entry burn (reducing aerothermal loads on the stage) and the final landing burn to slow the rocket down to safe landing velocity. In case of a downrange landing, only two burns are performed: the re-entry and the final landing burn.

\section{B. Results}

The results of the first design phase for launchers performing RTLS showed that those launchers reach sizes that are unfeasible regarding the delivered payload mass to GTO, see [2]. The LOX/LCH4 launcher with an upper stage $\Delta \mathrm{v}$ of $7.6 \mathrm{~km} / \mathrm{s}$ reached a GLOM of about 3800 tons of which 500 tons were propellant needed for the return manoeuvers. The payload fraction of this launcher is less than $0.2 \%$, thus rendering the RTLS performing launchers highly inefficient for GTO missions. Hence, it was decided that no further calculations shall be done for RTLS launchers within the second design phase. However, RTLS can be interesting for launching payload into less demanding orbits such as LEO or SSO orbits.

Fig. 2 shows the GLOMs of all launchers calculated in the first design phase performing a downrange barge landing. Generally, all hydrogen launchers are characterized by the letter $\mathrm{H}$, all methane launchers by the letter $\mathrm{C}$ (with TPC for triple point methane) and all propane launchers by the letter PR, followed by the amount of propellant in tons for the respective stage (two numbers are necessary for two stages). The upper stage $\Delta \mathrm{v}$ describes the $\Delta \mathrm{v}$ the second stage delivers after MECO excluding all losses. Hence, the higher the upper stage $\Delta \mathrm{v}$, the lower the MECO and separation velocity of the first stage.

As expected, the LOX/LH2 launchers are the lightest by GLOM with a noticeable mass advantage of the staged combustion launchers due to their higher engine performance. The LOX/propane launchers are slightly lighter than the LOX/methane launchers. Generally, the launchers have a lower GLOM with decreasing upper stage $\Delta \mathrm{v}$ due to 
the fact that the upper stage mass decreases. The first stage mass is driven by two counteracting effects; first, lighter upper stages lead to lighter lower stages, since the propellant carried in the first stage depends on the mass to be accelerated. Second, the lower stage needs to deliver more $\Delta \mathrm{v}$ (hence needs more propellant) with decreasing upper stage $\Delta \mathrm{v}$. However, the effect of decreasing second stage mass seems to have much more influence on the total GLOM in the upper stage $\Delta \mathrm{v}$ range from $6.6 \mathrm{~km} / \mathrm{s}$ to $7.6 \mathrm{~km} / \mathrm{s}$.

wst stage $\square$ 2nd stage $=$ Payload

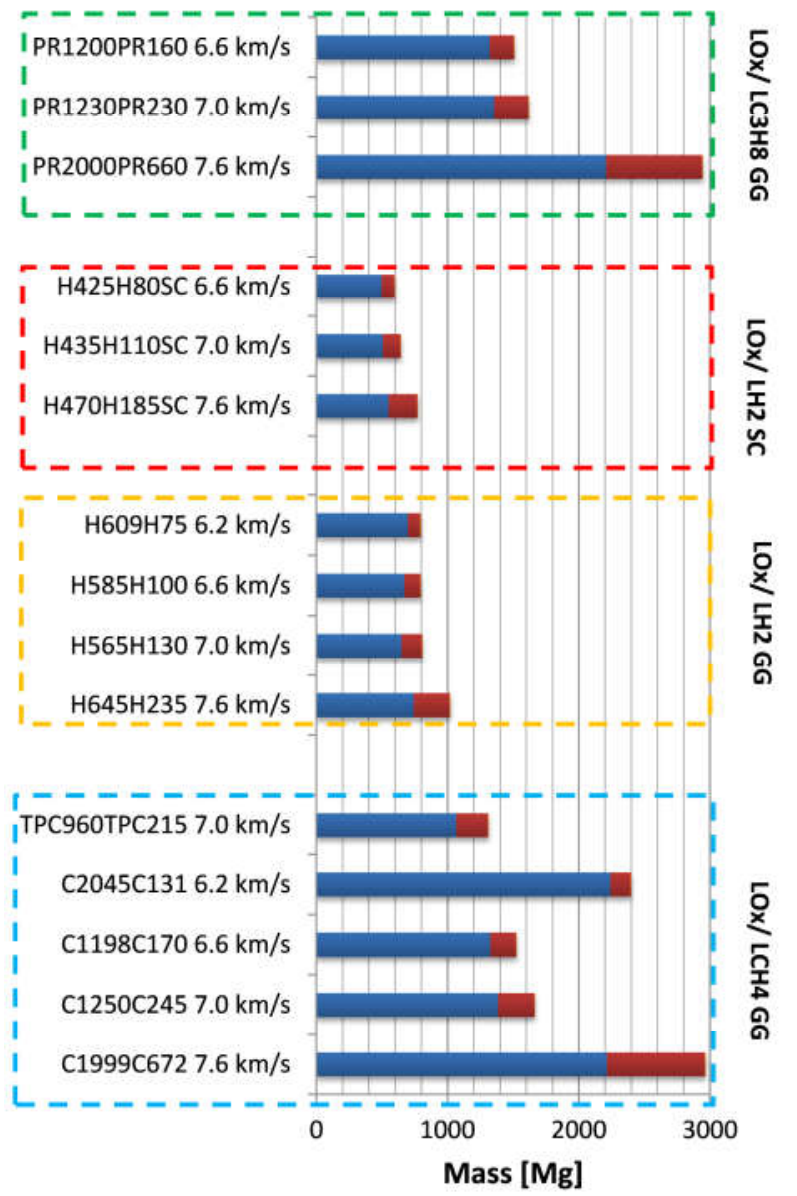

Fig. 2: GLOM of the LOX/propane, LOX/LH2 with staged combustion, LOX/LH2 with gas generator and the LOX/methane launchers of the first design phase extended from [2]

Nevertheless, the LOX/methane launchers clearly show that an optimum is reached between $6.6 \mathrm{~km} / \mathrm{s}$ and $7.0 \mathrm{~km} / \mathrm{s}$ upper stage $\Delta \mathrm{v}$ based on the observation that the GLOM of the $6.2 \mathrm{~km} / \mathrm{s}$ version is much higher than the GLOM of the $6.6 \mathrm{~km} / \mathrm{s}$ variant. This effect was also observed for the LOX/LH2 launcher but is much less pronounced which can be explained by a different behavior of the underlying SI curve.

The results of the preliminary design phase led to the conclusion that an upper stage $\Delta \mathrm{v}$ between $6.6 \mathrm{~km} / \mathrm{s}$ and $7.0 \mathrm{~km} / \mathrm{s}$ is favorable for downrange barge landings of the suggested launcher configuration. Therefore, the second design phase with a more detailed model was applied to the LOX/LH2, LOX/LCH4, LOX/LC3H8, and LOX/RP-1 launchers with an upper stage $\Delta v$ of $6.6 \mathrm{~km} / \mathrm{s}$. For an upper stage $\Delta v$ of $7.0 \mathrm{~km} / \mathrm{s}$ the LOX/LH2, LOX/LCH4 and LOX/RP1 launchers were designed.

\section{Preliminary VTVL Design Phase Assumptions}

\section{A. Main Propulsion Rocket Engines}

The systematic assessment of future RLV-stages and technical options, as intended in this study, requires the definition of generic engines with similar baseline assumptions in order to reach maximum comparability. Despite 
the engines being generic, their selected technical characteristics for simulation are strongly oriented towards data of existing types or previous or ongoing development projects, whenever possible.

The two rocket engine cycles most commonly used in first or booster stages are included in the study:

- Gas-Generator-cycle

- Staged-Combustion cycle.

The main combustion chamber (MCC) pressure is commonly set to $12 \mathrm{MPa}$ for the gas-generator type. This pressure is not far from the useful upper limit of this cycle but is assumed necessary to achieve sufficient performance for the RLV stages. Europe has considerable experience in this range with Vulcain 2 operating at 11.7 $\mathrm{MPa}$. In case of the staged-combustion engines, the main combustion chamber pressure is commonly fixed at $16 \mathrm{MPa}$. This moderate value in Russian or US perspective has been chosen considering the limited European experience in closed cycle high-pressure engines. Nozzle expansion ratios are selected according to optimum performance but also requirements of safe throttled operations when landing VTVL-stages. For the first stage engines data are calculated for expansion ratios of 20 for gas generator types and 23 for the staged-combustion variants.

The upper stage engines are derived from the first stage engines with the only difference being the expansion ratio. This value was set to 120 based on the results from the first structural index design cycle showing that the designed upper stage engine nozzle length with an expansion ratio of 180 exceeded the available length in the interstage. Furthermore, all other engine parameters are equal to those of the first stage (chamber pressure, engine cycle, turbopump efficiencies etc.).

All preliminary engine definitions have been performed by simulation of steady-state operation at $100 \%$ nominal thrust level using the DLR-tools lrp and ncc (nozzle contour calculation program) as well as the commercially available tool RPA (rocket propulsion analysis). Any potential requirements specific to transient operations or deepthrottling are not considered in this early design study. Common baseline assumption of all engines is a vacuum thrust in the $2200 \mathrm{kN}$-class. Although all engine massflows are scaled to the required thrust level of the individual launcher configuration, the underlying assumptions on component efficiencies (e.g. turbo $\neg$ pumps) are most likely no longer valid for smaller engines below $1000 \mathrm{kN}$. Turbine entry temperature (TET) is set around $750 \mathrm{~K}$ and kept in all cases below $800 \mathrm{~K}$ to be compatible with the increased lifetime requirement of reusable rocket engines.

Further, for all engines in this study regeneratively cooled combustion chambers are assumed with regenerative or dump-cooling of the down-stream nozzle extensions. The results based on these assumptions are shown in Table 1. Detailed information on the respective engine modelling is described in [1] and [6].

Table 1: LOX/RP-1, LOX/LC4H8, LOX/LCH4 and LOX/LH2 engine data

\begin{tabular}{|c|c|c|c|c|c|c|c|c|}
\hline \multirow{3}{*}{$\begin{array}{l}\text { Propellants } \\
\text { Parameter }\end{array}$} & \multicolumn{4}{|c|}{$L O X / R P-1$} & \multicolumn{4}{|c|}{$L O X / L C 3 H 8$} \\
\hline & \multicolumn{2}{|c|}{ 1st stage } & \multicolumn{2}{|c|}{ 2nd stage } & \multicolumn{2}{|c|}{ 1st stage } & \multicolumn{2}{|c|}{ 2nd stage } \\
\hline & $\begin{array}{c}\text { GG } \\
\varepsilon=20\end{array}$ & $\begin{array}{c}\mathrm{SC} \\
\varepsilon=23 \\
\end{array}$ & $\begin{array}{c}\text { GG } \\
\varepsilon=120\end{array}$ & $\begin{array}{c}\mathrm{SC} \\
\varepsilon=120\end{array}$ & $\begin{array}{c}\text { GG } \\
\varepsilon=20\end{array}$ & $\begin{array}{c}\mathrm{SC} \\
\varepsilon=23\end{array}$ & $\begin{array}{c}\text { GG } \\
\varepsilon=120\end{array}$ & $\begin{array}{c}\mathrm{SC} \\
\varepsilon=120 \\
\end{array}$ \\
\hline Engine MR [-] & 2.22 & 2.6 & 2.22 & 2.6 & 2.45 & 2.8 & 2.45 & 2.8 \\
\hline Sea level Isp [s] & 279 & 295 & - & - & 284 & 300 & - & - \\
\hline Vacuum Isp [s] & 310 & 317 & 338 & 353 & 315 & 339 & 344 & 359 \\
\hline Engine $\mathrm{T} / \mathrm{W}[-]$ & 112.1 & 109.4 & 92.4 & 72.3 & 101.9 & - & 86.4 & - \\
\hline
\end{tabular}




\begin{tabular}{|c|c|c|c|c|c|c|c|c|}
\hline \multirow{3}{*}{$\begin{array}{l}\text { Propellants } \\
\text { Parameter }\end{array}$} & \multicolumn{4}{|c|}{$\mathrm{LOX} / \mathrm{LCH} 4$} & \multicolumn{4}{|c|}{$L O X / L H 2$} \\
\hline & \multicolumn{2}{|c|}{ 1st stage } & \multicolumn{2}{|c|}{ 2nd stage } & \multicolumn{2}{|c|}{ 1st stage } & \multicolumn{2}{|c|}{ 2nd stage } \\
\hline & $\begin{array}{c}\begin{array}{c}\mathbf{G G} \\
\varepsilon=\mathbf{2 0}\end{array} \\
\end{array}$ & $\begin{array}{c}\mathrm{SC} \\
\varepsilon=23\end{array}$ & $\begin{array}{c}\text { GG } \\
\varepsilon=120\end{array}$ & $\begin{array}{c}\mathrm{SC} \\
\varepsilon=120\end{array}$ & $\begin{array}{c}\mathbf{G G} \\
\varepsilon=20 \\
\end{array}$ & $\begin{array}{c}\text { SC } \\
\varepsilon=23\end{array}$ & $\begin{array}{c}\text { GG } \\
\varepsilon=120\end{array}$ & $\begin{array}{c}S C \\
\varepsilon=120 \\
\end{array}$ \\
\hline Engine MR [-] & 2.5 & 3.25 & 2.5 & 3.25 & 6 & 6 & 6 & 6 \\
\hline Sea level Isp [s] & 289 & 310.5 & - & - & 366 & 394 & - & - \\
\hline Vacuum Isp [s] & 320 & 339 & 348 & 365 & 405.5 & 428 & 440.4 & 458.6 \\
\hline Engine T/W [-] & 97.5 & 66 & 82.7 & 57.5 & 98.1 & 73.5 & 82.4 & 70.2 \\
\hline
\end{tabular}

\section{B. Structure and Propellant System}

The structural masses of first and second stage propellant tanks, the interstage, the second stage's front skirt and the first stage's thrust frame were calculated using the DLR-SART tool $l$ sap (launcher structural analysis program). Several load cases from the GTO trajectory were defined and imposed on the structure (including margins for dynamic loads) to determine the structural layout necessary to withstand possible failure modes. The safety factor was chosen to be 1.25 , a standard value for unmanned launchers.

The tanks and the second stage front skirt were designed using a conventional stringer/frame approach with " $Z$ " - formed stringer and frames. The number of stringers and frames is subject to an optimization process within the program to determine the lightest configuration possible. The tanks are separated by a common bulkhead and built of the aluminum alloy AA2219. All tanks are pressurized with 3 bar which was chosen based on previous experience with launcher design and shall be subject to optimization in the future.

The interstage and fairing were modelled as an aluminum honeycomb structure with carbon fiber outer layers. Whereas the interstage mass is calculated with the tool $l s a p$, the fairing mass was calculated by scaling the mass of the Ariane 5 fairing with the respective surface area.

The first stage's thrustframe was modelled as a conical structure with " $Z$ " formed stringers and frames with the rocket body diameter at the front end and $0.5 \mathrm{~m}$ of diameter less at its rear end (see Fig. 3 for details). The thrustframe is covered by a skirt acting as protection against the aerodynamic loads during launch and re-entry.

Fig. 3 shows the structural model of the preliminary hydrogen launcher. The green parts are the front and rear skirt, the parts colored in red highlight the composite structures (interstage and fairing), the blue parts represent the tanks and the black lines display the outline of the tank domes.

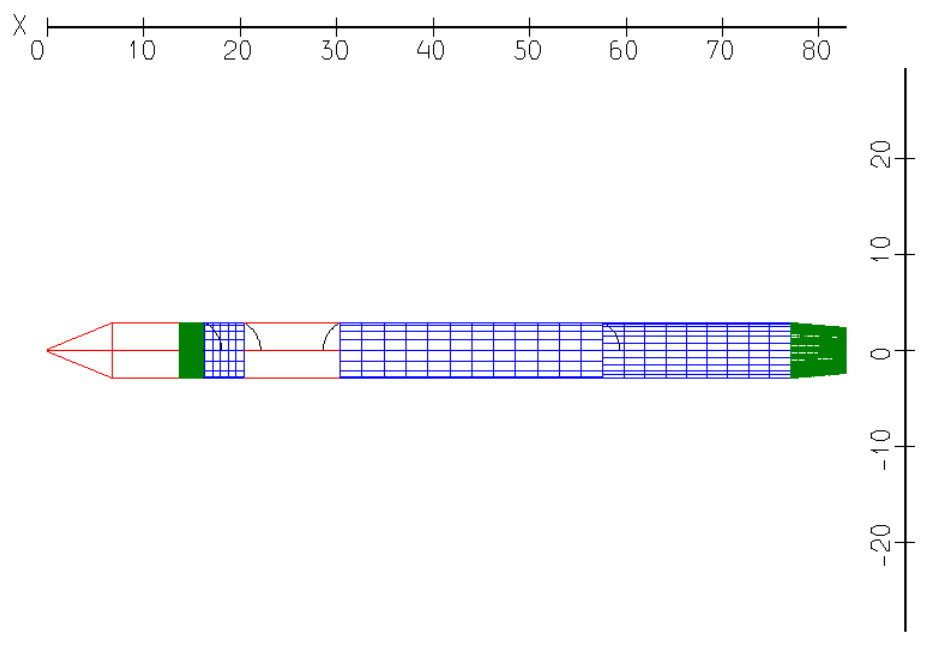

Fig. 3: Structure Model of the preliminary launchers

The propellant supply system including feedlines, fill/drainlines and the pressurization system was modelled using the SART tool pmp. This program is able to calculate the respective masses for these systems by calculating the propellant and pressurizing gas flow throughout the whole mission and thus sizing the required hardware. 

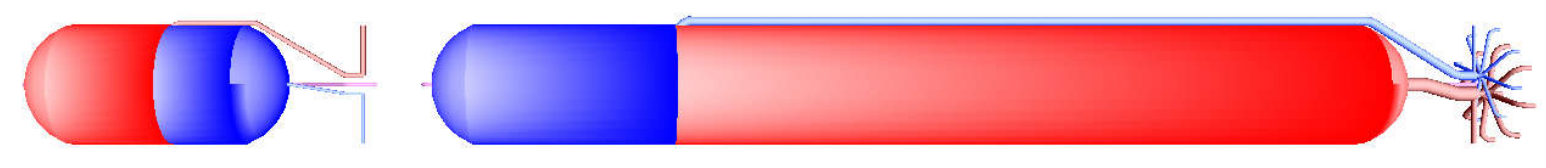

Fig. 4: Model of the propellant management system for a generic LOX/LH2 launcher

The model of the propellant system is shown in Fig. 4. The respective propellant system is that of the hydrogen launcher presented in detail in section V. The LOX tanks are colored in blue, the LH2 tanks in red. The first stage main propellant feedline is branched into several smaller feedlines to individually supply the engines at the rear end of the launcher. The pressurization lines run along the backside of the tanks and supply the LOX tank with gaseous oxygen and the LH2 tank with gaseous hydrogen. The hydrocarbon launcher LOX tanks are pressurized with gaseous oxygen and the fuel tanks are pressurized with the respective hydrocarbon in gaseous state except for the LOX/RP-1 configuration. In this case, the RP-1 tank is pressurized with helium which is stored in pressure tanks in the LOX tank.

The pmp tool also calculates the mass of the cryogenic insulation of the tanks. It is important to note that insulation was only considered a necessity in the case of LOX/LH2 launchers due to the low temperature of LH2. In the case of hydrocarbon launchers no insulation is used, since it adds mass and it is technically feasible to fly cryogenic propellants without insulation (e.g. Falcon 9 with LOX/RP-1).

\section{Recovery Hardware}

The VTVL first stages have to be equipped with hardware to enable the safe recovery of the first stage. Since the first stage shall be controllable not only in the exoatmospheric part of the return trajectory (with RCS) but also in the aerodynamic part, aerodynamic control devices are necessary. Furthermore, the landing of the first stage requires some kind of landing gear or landing legs. Currently only two operational VTVL launchers are active, the first one being the Blue Origin's "New Shephard" suborbital launcher and the second one being the Falcon 9 v1.1 FT first stage. The "New Shephard" launcher uses conventional fins, such as so-called "wedge fins", to control the aerodynamic forces during descent whereas the Falcon 9 uses grid fins as shown in Fig. 5. Furthermore, both launchers use landing legs with different unfolding mechanisms.

Since the Falcon 9 first stage mass is more in the order of the proposed launchers than the New Shephard's mass, the ENTRAIN launchers' fins and landing legs mass was calculated by scaling the respective masses of the Falcon 9 with the ENTRAIN launchers' dry mass. The masses of the Falcon 9 recovery hardware such as grid fin and landing leg masses were estimated using in-house tools and reverse engineering [7]. This scaling method will be replaced by a proper mass calculation using CFD calculations for the grid fins and landing dynamics and structural design considerations for the landing legs in the second part of the ENTRAIN study (see section VI). However, it is not decided yet if the VTVL launcher investigated in the second phase of the study will be equipped with grid fins or conventional fins.

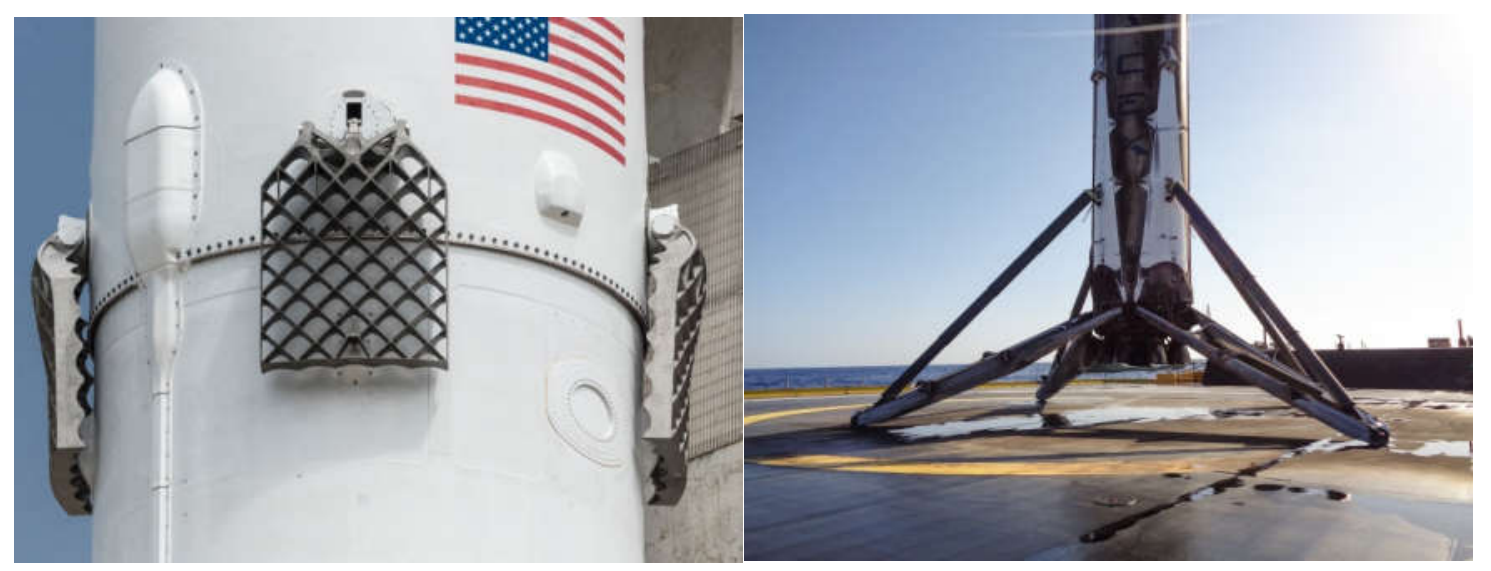

Fig. 5: Falcon 9 grid fins (left) and landing legs (right) (Photos by $\underline{\text { SpaceX/ }}$ CC0 1.0) 
Furthermore, the ENTRAIN launchers are equipped with a $2 \mathrm{~cm}$ thick layer of cork at the baseplate acting as a thermal protection system. The thickness was kept constant for all launchers since the re-entry occurs with more or less similar maximum heatflux. However, the dimensions of this TPS are difficult to determine since little to no actual data of aerothermodynamic behavior during a first stage suborbital re-entry are available. Hence, the TPS thickness is a first guess that shall be reevaluated and thoroughly investigated in the second part of the study by means of CFD calculations [8].

\section{Mass Model}

The mass model of the launchers was created using the SART tool stsm (Space Transport System Mass Estimation). This program uses empirical estimation formulas based on historical to calculate the masses of structural elements such as the rear skirt and subsystem masses such as engine equipment (including engine controllers and wiring), electrics and harness. Several subsystems were scaled with Ariane 6 subsystem masses such as the power system and batteries, the pyro stage - and fairing separation system, avionics, the RCS and the payload adapter.

All first stage structural parts, subsystems and TPS were subjected to a mass margin of $14 \%$ due to the fact that the mass estimation for RLVs is of higher uncertainty than that of an ELV launcher. The mass margin on the main engines was set to $10 \%$. All second stage elements were subjected to a mass margin of $10 \%$.

\section{E. Ascent and Descent Trajectories}

The ascent for the configurations presented in [1] was optimized assuming a direct insertion into the target GTO. However, due to the comparatively short total burn time of the two-staged launchers the argument of perigee was far from the $0^{\circ}$ or $180^{\circ}$. Those values are optimal for the final insertion into a GSO performed by the payload itself. In order to address this issue the ascent for the launchers shown hereafter was performed in two separate phases. First the second stage is inserted into a 140 x $330 \mathrm{~km}$ parking orbit. When the second stage passes over the equator the second burn is used to bring the payload onto the desired GTO with its perigee and apogee directly above the equator. While this ascent strategy does necessitate a reignitable second stage engine, this requirement is automatically fulfilled: The engine shared by both stages, as described in section A, has to be reignitable in order to allow the re-entry and landing of the first stage. However, propellant has to be reserved for the additional chilldown of the second stage engine.

Fig. 6 shows the ascent and descent trajectories of the LOX/LH2 launcher with an upper stage $\Delta v$ of $7.0 \mathrm{~km} / \mathrm{s}$ launched from Kourou. The first stage is supposed to land on a droneship or a similar floating device in the Atlantic Ocean. The descent trajectory was optimized with respect to minimum propellant required without violation of the boundaries. No specific landing site coordinates are defined so the optimization tool can find the optimal landing site for each launcher and separation velocity. Furthermore, specific landing conditions are prescribed that have to be fulfilled:

- Landing Fligh Path Angle: $90^{\circ} \pm 2^{\circ}$

- Landing Velocity: $0 \mathrm{~m} / \mathrm{s}-\max .2 .5 \mathrm{~m} / \mathrm{s}$

- Landing Altitude: $0 \mathrm{~m} \pm 10 \mathrm{~m}$

The low parking orbit leads to comparatively shallow ascent trajectories and thus to low flight path angles at stage separation. This has large benefits for the propellant mass needed for the re-entry burn since the shallower reentry trajectory allows the reduction of more velocity through aerodynamic forces without violating the trajectory constraints. These constraints were derived from structural calculations performed with the tool lsap [9] and from loads derived from SpaceX descent trajectories [3], identical to those used in [1]:

- Dynamic pressure of $<200 \mathrm{kPa}$

- Estimated heat flux of $<200 \mathrm{~kW} / \mathrm{m}^{2}$ with respect to a nose radius of $0.5 \mathrm{~m}$

- Lateral acceleration of $<3 \mathrm{~g}$ 


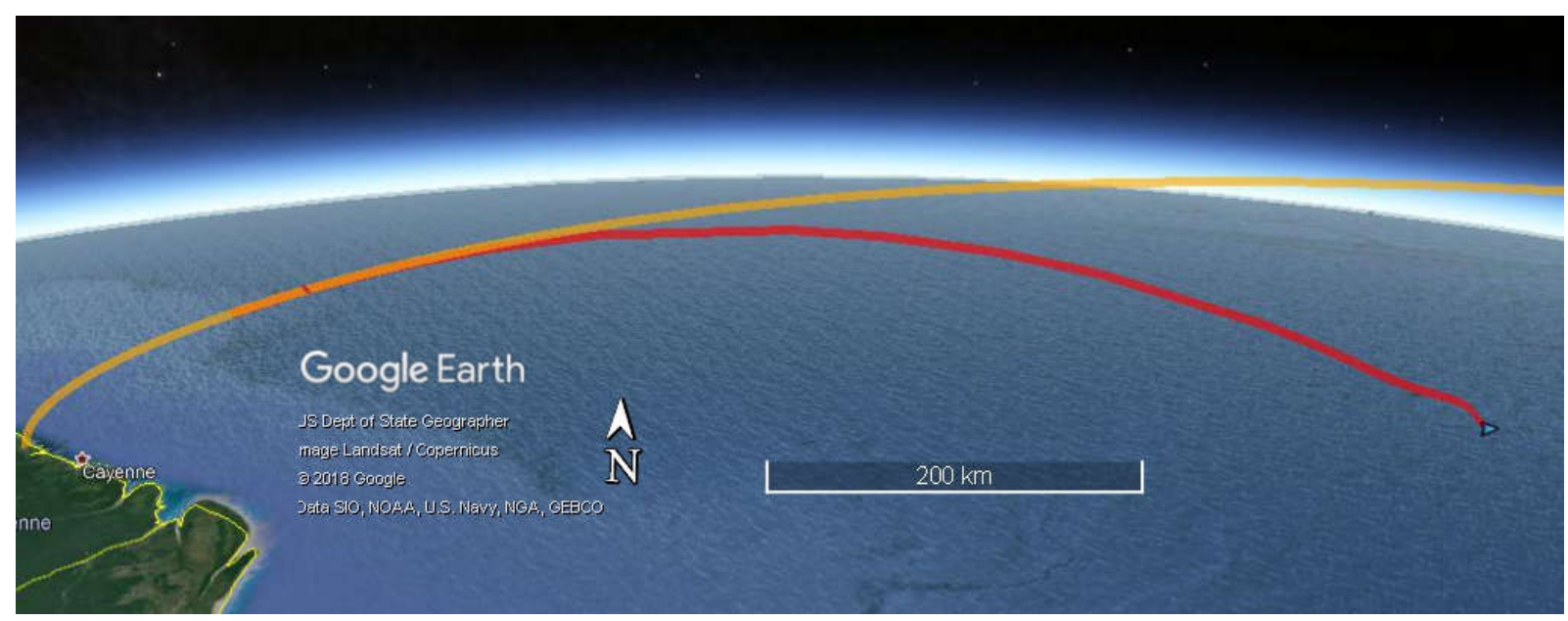

Fig. 6: Ascent trajectory (orange) to LEO parking orbit and descent trajectory (red) to landing ship of the LOX/LH2 gas generator $7.0 \mathrm{~km} / \mathrm{s}$ launcher

\section{Results}

In this section the following preliminary designed launchers are presented:

- LOX/LH2 with gas generator engines and an upper stage $\Delta \mathrm{v}$ of $6.6 \mathrm{~km} / \mathrm{s}$ and $7.0 \mathrm{~km} / \mathrm{s}$

- LOX/LH2 with staged combustion engines and an upper stage $\Delta \mathrm{v}$ of $7.0 \mathrm{~km} / \mathrm{s}$

- LOX/LCH4 with gas generator engines and an upper stage $\Delta \mathrm{v}$ of $6.6 \mathrm{~km} / \mathrm{s}$ and $7.0 \mathrm{~km} / \mathrm{s}$

- LOX/RP-1 with gas generator engines and an upper stage $\Delta \mathrm{v}$ of $6.6 \mathrm{~km} / \mathrm{s}$ and $7.0 \mathrm{~km} / \mathrm{s}$

- $\mathrm{LOX} / \mathrm{LC} 3 \mathrm{H} 8$ with gas generator engines and an upper stage $\Delta \mathrm{v}$ of $6.6 \mathrm{~km} / \mathrm{s}$

For further comparison with an actual TSTO RLV the Falcon 9 v1.1 FT has been added to the diagrams shown in the following section. It is important to note that all masses, performance values, re-entry data and engine data are based on in-house studies of the Falcon 9 [7].

\section{A. Launcher Mass \& Size}

Using the assumptions shown above, the launchers were designed to support the $7 \mathrm{t}(+500 \mathrm{~kg}$ design margin) payload into a GTO while returning the first stage to a barge. The geometric shape and dimensions of these launchers are shown in Fig. 7 alongside the Ariane 5 and the Falcon 9 for comparison. Additionally, Table 2 contains the main dimensions of the launchers and of the engines used in the specific launchers, based on the generic data shown in section A of chapter IV.

It is obvious at the first glance that the total size of the proposed launchers is quite large. While the hydrogen configurations do have a GLOM that is lower or similar to the Falcon 9, the low density of hydrogen leads to substantially larger overall dimensions. The large size results from a number of factors:

- High $\Delta \mathrm{v}$ target mission into GTO

- Reusability of first stage

- Two-Stage architecture

In all cases the configurations with an upper stage that delivers a $\Delta \mathrm{v}$ of $7 \mathrm{~km} / \mathrm{s}$ are noticeably lighter and smaller than their counterparts with $6.6 \mathrm{~km} / \mathrm{s}$ upper stages. However, while these launchers are larger, the expendable fraction is smaller in relative and absolute size. In this case the difference in total mass is so high that the larger upper stages seem more appealing in any case, but these secondary effects have to be considered in the second part of the study. 


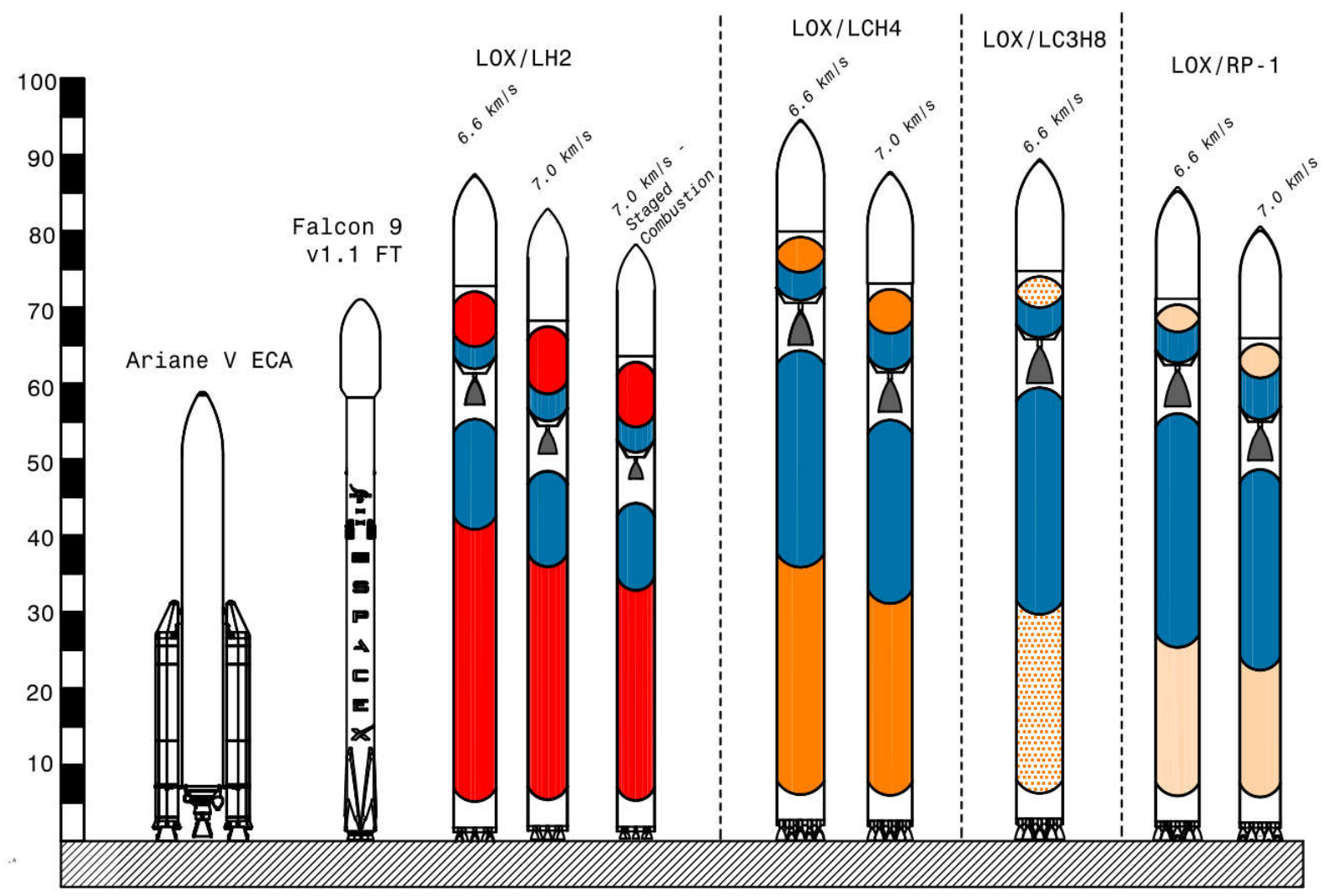

Fig. 7: Ariane 5, Falcon 9 v1.1 FT, DLR LOX/LH2, LOX/LCH4, LOX/LC3H8 and LOX/RP-1 launchers

It is important to note that the relative reduction in GLOM between the configurations with $6.6 \mathrm{~km} / \mathrm{s}$ and 7.0 $\mathrm{km} / \mathrm{s}$ upper stage $\Delta \mathrm{v}$ is more pronounced for the hydrocarbon launchers (-22\% reduction of GLOM) compared to the hydrogen launcher (-17.5\% reduction). This can be explained by the lower Isp of the hydrocarbons in combination with the higher $\Delta v$ demanded of the first stage of the $6.6 \mathrm{~km} / \mathrm{s}$ versions. Furthermore, the increase in first stage velocity leads to higher re-entry velocities and thus more propellant for deceleration of the stage. This factor also has a larger impact on the hydrocarbon stages, as their higher ballistic coefficient necessitates the use of more propulsive deceleration during descent than the hydrogen stages.

Compared to the hydrocarbons the hydrogen launchers have a fraction of the GLOM, shown in Fig. 8, and even the overall size of the launchers is noticeably smaller. The differences between these two groups are not limited to the general size and mass but can also be found in a number of other parameters. While the hydrogen launchers only employ 9 engines in the first stage, the hydrocarbon launchers need far more engines in the first stage, namely 13 17. This is caused by the requirement that the first and second stage use the same engine, albeit with different expansion ratios. Thus the number of engines in the first stage is the most important parameter in determining the thrust-to-weight ratio of the second stage, since the thrust-to-weight ratio of the entire launcher is kept constant at about 1.4 at lift-off. As the hydrocarbon upper stages are smaller relative to their first stages, this leads to the very high number of first stage engines shared by all shown hydrocarbons configurations. Otherwise the upper stage engine would be too heavy and detract from the overall performance. The specific engine data for each launcher can be found in Table 2 .

Upon close inspection of the geometries shown in Fig. 7 further differences between the hydrogen and hydrocarbon launchers can be seen: The fuel tank of the upper stage for hydrocarbon version becomes very small and the cylindrical portion becomes a small fraction of the total tank length. This leads to comparatively inefficient structures so that in these cases the higher density of the fuel is not a purely beneficial aspect. As might be expected this issue is worst for the hydrocarbon with the highest density: RP1. The impact of this effect on the structural index can be clearly seen in Fig. 10 and will be discussed in the following paragraph. For individually optimized 
stages it might be beneficial to use a non-integral fuel tank or decrease the diameter or the height of the tank domes or to put the LOX tank above the RP-1 tank.

Within the hydrocarbons the methane launchers are largest, followed by propane and finally the kerosene versions even though the GLOM are similar, as can be seen in Fig. 8. This is caused by the lower bulk density of the methane/oxygen propellant combination.

Table 2: Launcher and engine data

\begin{tabular}{|c|c|c|c|c|c|c|c|c|c|}
\hline \multirow{2}{*}{$\begin{array}{l}\text { Propellant combination } \\
\text { Engine Cycle }\end{array}$} & & \multicolumn{3}{|c|}{ LOX/LH2 } & \multicolumn{2}{|c|}{ LOX/LCH4 } & \multirow{2}{*}{$\begin{array}{l}\text { LOX/ } \\
\text { LC3H8 }\end{array}$} & \multicolumn{2}{|c|}{ LOX/RP-1 } \\
\hline & & GG & GG & SC & GG & GG & & GG & GG \\
\hline $2^{\text {nd }}$ stage $\Delta v$ & {$[\mathbf{k m} / \mathbf{s}]$} & 6.6 & 7.0 & 7.0 & 6.6 & 7.0 & 6.6 & 6.6 & 7.0 \\
\hline \multicolumn{10}{|l|}{$1^{\text {st }}$ stage } \\
\hline No. of engines & {$[-]$} & 9 & 9 & 9 & 17 & 15 & 15 & 15 & 13 \\
\hline Single Engine Thrust (sea level) & {$[\mathrm{kN}]$} & 807 & 764 & 560 & 1215 & 1085 & 1363 & 1355 & 1236 \\
\hline \multicolumn{10}{|l|}{$2^{\text {nd }}$ stage } \\
\hline Engine Thrust (vacuum) & {$[\mathrm{kN}]$} & 972 & 830 & 653 & 1464 & 1311 & 1653 & 1637 & 1495 \\
\hline \multicolumn{10}{|l|}{ Total Launcher } \\
\hline Height & {$[\mathrm{m}]$} & 87.3 & 82.8 & 78.1 & 94.4 & 87.6 & 89.3 & 85.7 & 80.5 \\
\hline Diameter & {$[\mathrm{m}]$} & 5.6 & 5.3 & 5.0 & 6.2 & 5.8 & 6.1 & 5.8 & 5.4 \\
\hline GLOM & {$[\mathbf{t}]$} & 541 & 447 & 367 & 1491 & 1165 & 1518 & 1462 & 1152 \\
\hline
\end{tabular}

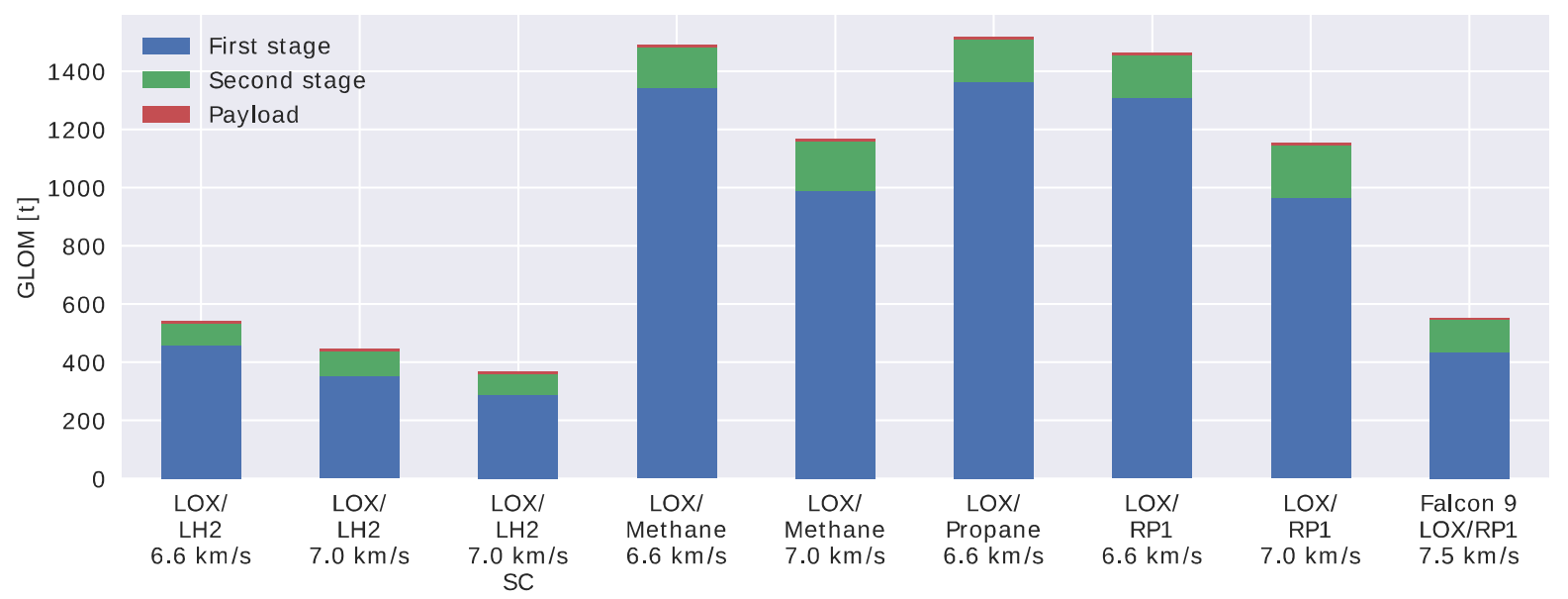

Fig. 8: GLOM of DLR-SART launchers and Falcon 9 v1.1 FT

Fig. 8 shows the GLOM of all launchers alongside the Falcon 9 as a comparison. It should however be noted that the performance of the Falcon 9 into a GTO is not identical; the current version of the Falcon 9 v1.1 FT can deliver approximately $5.5 \mathrm{t}$ to GTO with a first stage downrange barge landing. Furthermore, the upper stage of the Falcon 9 delivers around $7.5 \mathrm{~km} / \mathrm{s}$ [7]. The LOX/LC3H8 launcher with a $6.6 \mathrm{~km} / \mathrm{s}$ upper stage exhibits the largest GLOM of all investigated stages, followed by the $6.6 \mathrm{~km} / \mathrm{s}$ versions of methane and kerosene. However the GLOMs of these three launchers are so similar that no final conclusions regarding superiority of one concept should be drawn, as the margin of error in these preliminary designs is larger than the difference in GLOM. The comparison of dry mass, however, does allow some conclusions which are discussed in the following paragraph. 


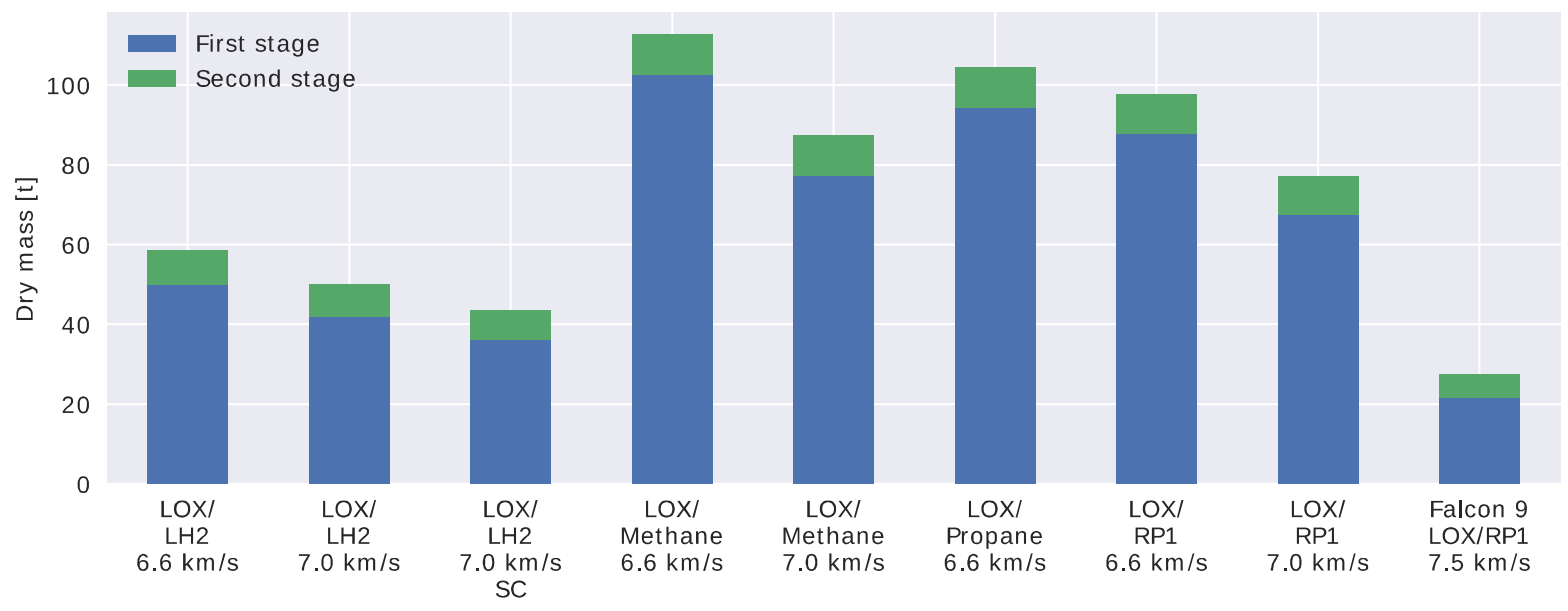

Fig. 9: Dry mass of DLR-SART launchers and Falcon 9 v1.1 FT

The dry mass of the investigated configurations can be seen in Fig. 9. While this paper does not contain any cost estimations, dry mass can be used as a rough indicator for cost, since the cost of the propellant is usually negligible for liquid rocket stages. While there still exists a large difference between the hydrocarbons and their hydrogen counterparts, the magnitude of difference is much smaller for the dry mass than for GLOM. The differences within the hydrocarbons, however, are magnified, compared to the trends visible for the GLOM: The kerosene launchers have the lowest dry mass of the hydrocarbons, followed by propane and methane. The relative difference between the individual hydrocarbons is increased for the dry mass compared to the GLOM since the denser hydrocarbons have a similar GLOM but a smaller SI, as can be seen in Fig. 10. This can also be clearly observed when comparing the kerosene and methane $7.0 \mathrm{~km} / \mathrm{s}$ launchers. Their GLOM is virtually identical but the kerosene version has a noticeably smaller dry mass. For the comparison of the gas-generator and staged combustion hydrogen launchers this trend is exactly opposite: While the version using staged-combustion engines has a GLOM that is lower by $18 \%$, the reduction of dry mass is only $13 \%$. This is caused by the reduction in propellant loading, which leads to higher structural indices for the smaller stages of the staged-combustion version.

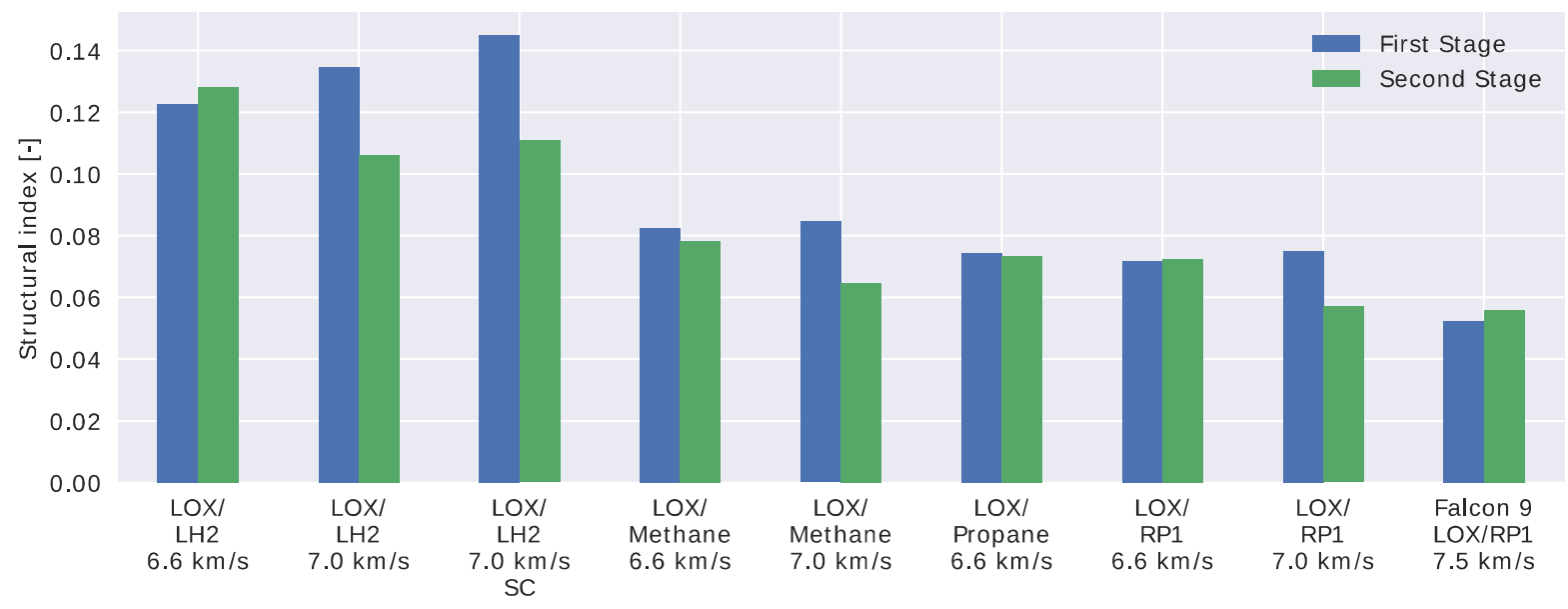

Fig. 10: SI of DLR-SART launchers and Falcon 9 v1.1 FT

In Fig. 10 the structural indices of the investigated configurations are shown. The structural index here is defined as

$$
S I=\frac{m_{d r y}}{m_{\text {prop }}}
$$


The dry mass includes the engines of the stage and for the upper stage the fairing mass. As expected the hydrogen stages have the highest structural indices and kerosene the lowest. In contrast to conventional ELV launchers the first stages have structural indices similar to or higher than the structural index of the second stage. In ELVs the upper stage usually has the higher structural index since they are much smaller than their first stages. The reverse behaviour for the investigated launchers is caused by the additional mass of the recovery hardware in the first stage needed for the barge landing.

When comparing the structural indices of the different staging options it becomes apparent that the upper stages of the $6.6 \mathrm{~km} / \mathrm{s}$ versions have noticeably higher structural indices than their $7.0 \mathrm{~km} / \mathrm{s}$ counterparts. This is caused by two factors: first, they need to deliver less $\Delta \mathrm{v}$ and thus have a lower propellant loading. This generally leads to a higher structural index, since not all subsystems scale with propellant loading. Second, as the launcher has a constant diameter the decreasing propellant loading of the second stage leads to suboptimal tank structures as discussed in the previous section.

The hydrogen launchers' first stages all have a SI in the range of $12.2 \%$ to $14.5 \%$, the second stage's SI range from $10.6 \%$ to $12.8 \%$. As a comparison, the second stage SI of the Saturn V was about $10 \%$ bearing around 450 tons of propellant. The respective third stage SI was in the order of $12 \%$ with a propellant loading of 106 tons. Hence, the Saturn V third stage has a similar propellant loading as the second stage of the $7.0 \mathrm{~km} / \mathrm{s}$ ENTRAIN hydrogen launcher with GG-cycle engines and 77 tons of propellant loaded. The structural index, however, is lower for the ENTRAIN launcher which is contrary to what is expected. This can be explained by the fact that the ENTRAIN launchers are designed to carry a payload of up to 7.5 tons to GTO while the Saturn V third stage was designed to carry up to 50 tons of Apollo spacecraft plus lunar lander, thus posing significantly more loads on the structure.

While for methane and propane no comparison to existing launchers can be made, the kerosene upper stages are similar in size to the Soyuz-FG first stage, that has a structural index of ca. 7\% (with engines) with a GLOM of approximately 100 tons. The $6.6 \mathrm{~km} / \mathrm{s}$ kerosene upper stage has a higher propellant loading of $133 \mathrm{t}$ and a similar SI of $7.25 \%$. While the $7.0 \mathrm{~km} / \mathrm{s}$ kerosene upper stage has a noticeable lower SI of $5.6 \%$ it also has a substantially higher propellant loading of 165t. This comparison however has to be taken with some care as the Soyuz-FG first stage has a very unique geometry and is subjected to other loads than an upper stage.

The comparison to existing stages in general is limited to the upper stages since the lower stages include recovery hardware, such as grid-fins and the landing legs and thus are heavier than comparable ELV stages. The only operating stage with these types of systems is the Falcon 9, also shown in Fig. 10, and that has extremely low structural indices, caused by propellant densification, modern manufacturing methods and the use of aluminumlithium alloys. This options will be also considered in the second half of the ENTRAIN study but were neglected for the preliminary design phase. Even for the upper stages, their large size prevents a useful comparison to existing upper stages since, with the exception of the aforementioned third stage of the Saturn 5, none have comparable size.

Overall these comparisons indicate that the methods used within this study result in feasible structural indices.

\section{Payload into other orbits}

The comparison of the different design options is biased by the target orbit and architecture. The high $\Delta \mathrm{v}$ required for a GTO mission with reuse of the first stage will favor propellants with higher specific impulse, even if their other properties (i.e. density) lead to higher structural indices. In order to assess this impact, the performance of the ENTRAIN launchers into a circular $800 \mathrm{~km}$ LEO as an ELV was analyzed. The results of these calculations can be seen in Table 3. However, they should be used with care, since the structural design of these stages was not reevaluated for these large payloads. It is to be expected that the second stage has to be reinforced in order to carry such large payload and it can also be assumed that the fairings would have to be resized for payload of that size. Also the large payloads severely impact the staging of the launchers, so that the stage separation conditions are no longer comparable and might be optimal for one case and suboptimal for another. Nevertheless, some general observations can be made based on this data.

Table 3: Payload of the ENTRAIN launchers into LEO as an ELV

\begin{tabular}{lllllllll}
\hline Configuration & LOX/ & LOX/ & LOX/ & LOX/ & LOX/ & LOX/ & LOX/ & LOX/ \\
& LH2 & LH2 & LH2 & LCH4 & LCH4 & LC3H8 & RP1 & RP1 \\
& $6.6 \mathrm{~km} / \mathrm{s}$ & $7.0 \mathrm{~km} / \mathrm{s}$ & $7.0 \mathrm{~km} / \mathrm{s}$ & $6.6 \mathrm{~km} / \mathrm{s}$ & $7.0 \mathrm{~km} / \mathrm{s}$ & $6.6 \mathrm{~km} / \mathrm{s}$ & $6.6 \mathrm{~km} / \mathrm{s}$ & $7.0 \mathrm{~km} / \mathrm{s}$ \\
& GG & GG & SC & GG & GG & GG & GG & GG \\
\hline $\begin{array}{l}\text { Payload ELV } \\
\text { LEO [t] }\end{array}$ & 30.8 & 25.8 & 21.6 & 50.0 & 37.1 & 45.9 & 44.2 & 36.1 \\
\hline
\end{tabular}


Fig. 11 shows the ratio of dry mass to payload mass of the LEO-ELV versions of the ENTRAIN launchers. It represents the number of $\mathrm{kg}$ of dry mass needed to launch $1 \mathrm{~kg}$ of payload into the target orbit. While the hydrogen stages still retain their edge over the hydrocarbon-fueled launchers, it is severely reduced and might be entirely negated by that fact that hydrogen stages can be expected to be more complex in production, operation and ground handling due to the use of deep-cooled cryogenics. Hence, the costs are expected to be higher for same sized hydrogen launchers compared to hydrocarbon launchers.

Additionally, the difference between the different staging velocities is also reduced and the dry mass to payload mass almost identical for launchers using the same propellant combination. The benefit of the staged combustion cycle is entirely negated, but this is assumed to be caused by the aforementioned suboptimal staging of the launcher.

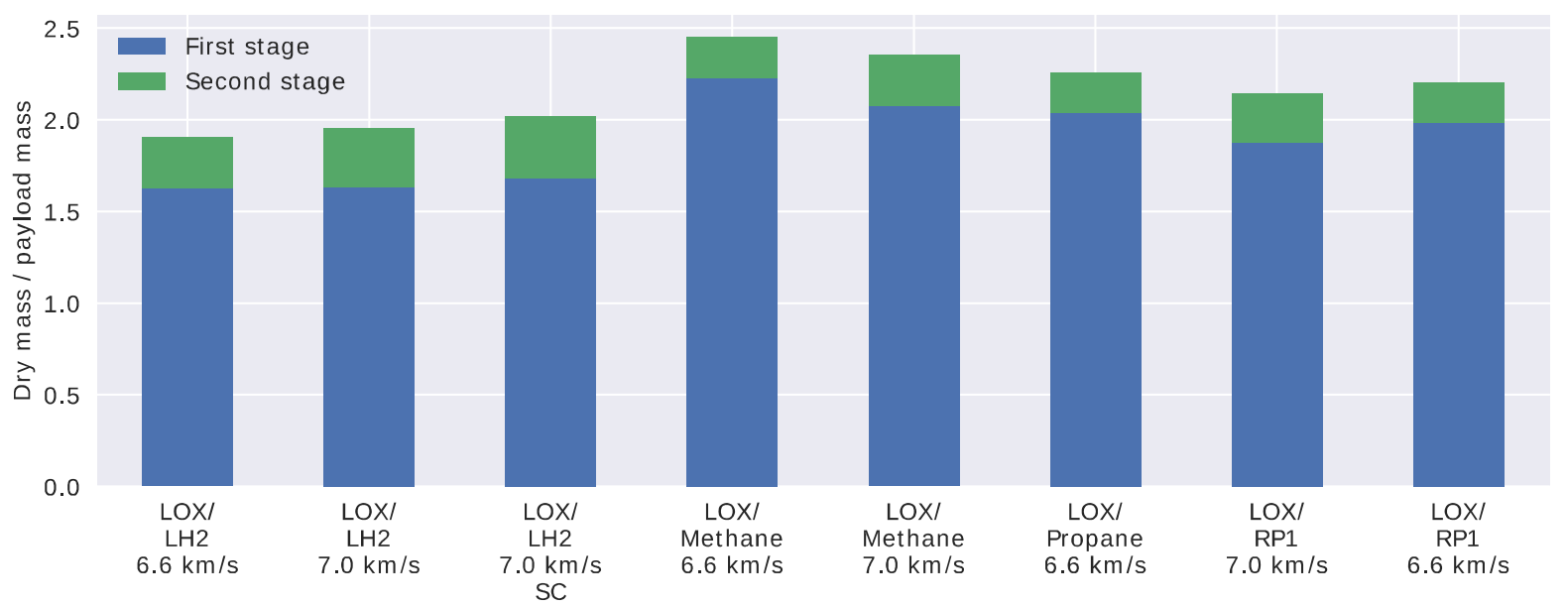

Fig. 11: Dry mass to payload mass ratio for payload to LEO

\section{B. Re-entry Trajectory}

The re-entry profile for all discussed launchers is shown in Fig. 12. The launcher with smaller upper stages (6.6 $\mathrm{km} / \mathrm{s} \Delta \mathrm{v}$ ) re-enter the atmosphere significantly faster since their separation velocity is higher compared to the larger upper stages $(7.0 \mathrm{~km} / \mathrm{s} \Delta \mathrm{v})$. The first bend in the graph marks the beginning of the re-entry burn as described in chapter IV. The re-entry burn typically starts in an altitude of $55 \mathrm{~km}$ to almost $70 \mathrm{~km}$. The timing and duration are mainly driven by the heatflux boundary described in section IV.E since all other aerodynamic loads are well within its limits while the heatflux boundary is reached in every re-entry trajectory. The launchers use between 3 and 7 engines, depending on the propellant combination, to obtain a similar thrust-to-weight ratio during the burn.

At the end of the re-entry burn the difference between the two staging options is negligible and the trajectories vary depending on the bulk density of the used propellants. This was to be expected, since the ballistic coefficient has a major impact on the trajectory and it is much lower for the voluminous hydrogen stages with a comparatively low dry mass and large surface area. This can be clearly seen in the Fig. 12 as the re-entry burn of the hydrogen stages does not decelerate the returning stages as much as the hydrocarbon stages. In a nutshell, the lower ballistic coefficient enables the hydrogen stages to shed more velocity during the non-propulsive phase of the re-entry without violating the trajectory constraints. Since the hydrocarbon stages all have similar ballistic coefficients, their re-entry burns end at similar velocities and heights.

The landing burn occurs with multiple engines being ignited at the begin (between 3 and 5) of the burn but only one engine still running at the moment of landing. This simplifies the controllability during the final landing phase and even allows for hovering for some of the stages. The profile for the final landing burn is virtually identical for all stages, since the gravitational and propulsive forces dominate during that phase. 


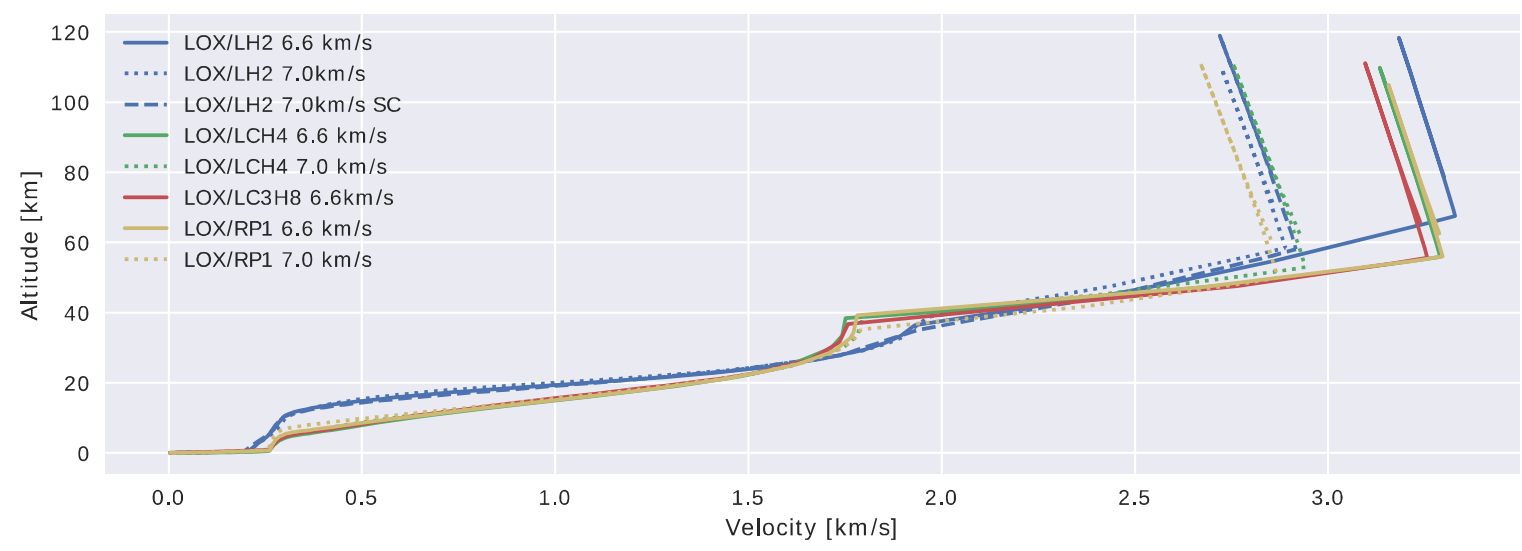

Fig. 12: Re-entry profiles of VTVL with varying separation conditions and propellants

\section{Conclusion \& Outlook}

The comparison of different propellants and engine cycles showed that the general size of hydrogen such as hydrocarbon launchers with reusable VTVL booster stages increases significantly compared to common ELVs. However, the GLOMs of the hydrogen launchers are comparable to operational launch vehicles like the Falcon 9 v1.1FT as RLV (5.5 tons payload to GTO) or the Ariane 5 as ELV ( $\sim 11$ tons to GTO). As expected using LOX/LH2 results in the lightest launchers followed by LOX/RP-1, then LOX/LCH4 and finally LOX/LC3H8 . The GLOM of the hydrocarbons is around 2.8 times higher compared to the hydrogen launchers. However, the differences within the hydrocarbons themselves are minimal.

Nevertheless, the differences between the hydrocarbon launchers become significant when comparing the dry mass. The use of LOX/RP1 leads to the lowest dry mass, followed by LOX/LC3H8 and finally LOX/LCH4. Concerning the comparison of the two cryogenic hydrocarbon fuels, LCH4 and LC3H8, the LOX/LCH4 launcher has a slightly lower GLOM but a higher dry mass so that LC3H8 should not be disregarded as a possible fuel choice, since it also offers significant subcooling potential.

These comparisons are significantly impacted by the choice of reference mission and first estimations show that the difference between the hydrocarbons and hydrogen as fuel are reduced for reference mission with lower $\Delta \mathrm{v}$ requirements.

The launchers with an upper stage $\Delta \mathrm{v}$ of $7.0 \mathrm{~km} / \mathrm{s}$ are generally lighter than their $6.6 \mathrm{~km} / \mathrm{s}$ counterparts. The relative decrease, however, is around $22 \%$ for the hydrocarbons compared to $17 \%$ for the hydrogen launchers. Hence, it seems favorable to design a VTVL launcher with a second stage delivering $7.0 \mathrm{~km} / \mathrm{s}$, but secondary effects such as a lower ratio of reused to expended hardware mass have to be taken into consideration. Since the ratio of reused to expended hardware can significantly influence the launch costs some kind of cost estimation will have to be performed to evaluate the significance of this ratio. This will be done in the second part of the ENTRAIN study, described in detail later in this section.

In addition to the VTVL presented and discussed within this presentation VTHL booster stages are also being investigated in parallel [9]. The methods and results for these winged configurations will be presented in [10], while a comparison of winged and propulsive reuseable stages will be presented at the IAC in Bremen [11]. At that point in time the first ENTRAIN study will be completed and the work on the second part of the study, ENTRAIN 2, shall commence.

As mentioned above the work presented herein focuses on maximum comparability between different reusability options, stagings, propellant combinations and engine options and thus assumes constant boundary conditions for all launchers. In contrast, the purpose of the ENTRAIN 2 study is the evaluation of as realistic and detailed as possible launcher designs. Only two configurations, one winged one non-winged, will be selected and investigated. Both configurations will be optimized around their individual parameters and thus will not be as comparable as the options discussed herein, but instead will show more realistic view of how European reusable boosters could be actually implemented. The final goal of the ENTRAIN 2 study is the evaluation of the feasibility and the technical and financial consequences of using such reusable booster stages for the European use case. The focus on two configurations will allow the use of high-fidelity and computationally expensive tools developed by DLR. This will 
enable the investigation of some critical phenomena that cannot be assessed with the preliminary methods, e.g. the controllability or the heat transfer into the base plate and the engine nozzle during the aerodynamic phases of reentry and the structural integration of landing legs and grid fins into the core stage structure

The preliminary design phase of VTVL launchers presented in this paper has already shown a major difficulty linked to the design of VTVL stages: the difficulty of predicting the impact of the re-entry aerothermal loads on the stage hardware. Minimizing this impact is of crucial importance for a viable RLV since only low refurbishment costs render an RLV superior to a comparable ELV. However, this impact is difficult to predict in theory without experiencing the actual re-entry loads. Hence, DLR is currently working on two flight demonstrators that are representing both the VTVL and the VTHL method. The project "CALLISTO" (Cooperative Action Leading to Launcher Innovation in Stage Tossback Operations), in cooperation with CNES and JAXA, is a reusable VTVL flight demonstrator that will be launched from Kourou to perform vertical landings and maneuvers similar to that of a full-scale reusable VTVL stage [12]. On the other hand, the DLR project "ReFEx" (Reusability Flight Experiment) is a winged flight demonstrator that shall perform a re-entry with transition from hypersonic to subsonic flight similar to that of a VTHL booster stage [14]. This demonstrator is planned to be launched on a sounding rocket from the rocket test facility of Woomera, South Australia. The scientific data gathered by both demonstrators during flight shall be used to improve the design of reusable booster stages as presented in this paper.

\section{Acknowledgments}

This work has been performed within the X-TRAS project funded by DLR. The authors would further like to acknowledge the contribution of everyone in the X-TRAS team involved in design process of the herein presented VTVL launchers.

\section{References}

[1] Stappert, S., Wilken, J., Sippel, M., Dumont, E., “Assessment of European Reusable VTVL Booster Stage”, Space Propulsion Conference, , Seville, 2018, https://elib.dlr.de/120200/

[2] Dumont, E., Stappert. S, Wilken J., "Evaluation of a Future Reusable Ariane VTOL Booster”, D_123131, IAC 201725 - 29 September 2017, Adelaide, Australia, http://elib.dlr.de/114430/

[3] Stappert, S., Dumont, E.: Reusability of launcher vehicles by the method of SpaceX, SART-TN007/2016, 2016, http://elib.dlr.de/104992/

[4] Sippel, M., Manfletti, C., Burkhardt, H., Longterm/strategic scenario for reusable booster stages, Acta Astronautica, Volume 58, Issue 4, February 2006, pp 209-221, DOI: 10.1016/j.actaastro.2005.09.012

[5] Patentschrift (patent specification) DE $10147 \quad 144$ C1, Verfahren zum Bergen einer Stufe eines mehrstufigen Raumtransportsystems, released 2003.

[6] Sippel, M., Wilken J.: "Preliminary Component Definition of Reusable Staged-Combustion Rocket Engine", Space Propulsion 2018 conference, Seville, May 2018

[7] Stappert, S., Sippel, M.: Critical Analysis of SpaceX Falcon 9 v1.2 Launcher and Missions, SART TN-009/2017, 2017

[8] Ecker, T., Zilker, F., Dumont, E. et al.: "Aerothermal Analysis of Reusable Launcher Systems during Retro-Propulsion Reentry and Landing”, Space Propulsion 2018 conference, Seville, May 2018

[9] Sippel, M. Stappert, S., Bussler, L.: "Systematic Assessment of a Reusable First-stage Return Options", IAC-17-D2.4.4, 68 International Astronautical Congress, Adelaide, Australia, 25-29 September 2017, http://elib.dlr.de/114960/

[10] Bussler, L., Dietlein, I., Dumont, E., Sippel, M., Stappert, S., Wilken, J., “Assessment of VTVL and VTHL Reusable First Stages”, International Conference on High-Speed Vehicle Science \& Technology 2018, Moscow, Russia

[11] Wilken, J., Stappert, S., Bussler, L., Sippel, M., Dumont, E., "Future European Reusable Booster Stages: Evaluation of VTHL and VTVL Return Methods", IAC-2018 D2.4.1, IAC 2018, Bremen, Germany

[12] Dumont, E., Ecker, T., Chavagnac, C. et al.: "Callisto - Reusable VTOL launcher first stage demonstrator", Space Propulsion 2018 conference, Seville, May 2018

[13] Klevanski, J, Ecker, T., Riehmer, J., Reimann, B., Dumont, E., Chavagnac, C.: Aerodynamic Studies in Preparation for CALLISTO -Reusable VTVL Launcher First Stage Demonstrator, IAC 2018-D2.6.3, IAC 2018, Bremen, Germany

[14] Bauer, W., Rickmers, P., Kallenbach, A. et al.: "Upcoming DLR Reusability Flight Experiment", IAC-17-D2.6.1, IAC 2017 25 - 29 September 2017, Adelaide, Australia, http://elib.dlr.de/116879/ 